\title{
Low Immunogenic Potential of Human Neural Stem Cells
}

\author{
L. De Filippis ${ }^{1}$, L. Rota Nodari ${ }^{1}$ and Maurizio Gelati ${ }^{2}$ \\ ${ }^{1}$ Department of Biotechnologies and Biosciences, Università Milano Bicocca, Milan, \\ ${ }^{2}$ Laboratorio Cellule Staminali, Cell Factory e Biobanca, \\ Azienda Ospedaliera "Santa Maria", Terni
}

Italy

\section{Introduction}

Grafting of neural stem cells into the mammalian central nervous system (CNS) has been performed for some decades now, both in basic research and clinical applications for neurological disorders such as Parkinson's and Huntington's disease, stroke, and spinal cord injuries. Albeit the "proof of principle" status that neural grafts can reinstate functional deficits and rebuild damaged neuronal circuitries, many critical roadblocks have still to be overcome to reach clinical applications. Among these are the manifold immunological aspects that are encountered during the graft-host interaction in vivo. In this chapter we will elucidate different aspects of cellular therapy, particularly using CNS derived stem cells and their ability to modulate immune system in order to avoid rejection and/or affect inflammatory reactions related to neurodegenerative diseases.

\section{Neural transplantation for the therapy of neurodegenerative diseases}

\subsection{NSCs: Use into humans and animal models}

Grafting of neural stem cells (NSCs) into the mammalian central nervous system in association with their ability to induce active neurogenesis in the adult CNS has fostered a flurry of studies to investigate the exploitation of NSC for the therapy of neurodegenerative disorders including both genetic diseases like Metachromatic Leukodystrophy (MLD), Huntington's Disease (HD), Alzheimer's Disease (AD) (sporadic) and idiopathic diseases like Parkinson's Disease (PD), AD, Multiple Sclerosis (MS), Amyotrophyc Lateral Sclerosis (ALS), stroke.

Regenerative medicine strongly relies on the capacity of intrinsic subsets of cells to replenish the damaged ones. Although for a long time the CNS was thought to be a "perennial", i.e. post-mitotic tissue, the discovery of active neurogenesis in the adult mammalian brain has debunked this dogma and spurred ongoing research efforts to focus on stem/ precursor cell therapy to treat neurodegeneration and neurotrauma.

Given the intrinsic resilience of NSC to fast proliferation and prompt expansion in vivo, the spontaneous recovery of most CNS injuries remains limited and a feasible strategy to support the endogenous NSC-mediated therapy would be the autologous transplantation of adult stem cells from various tissue compartments than the CNS. Different sources of stem cells have been proposed, but they mostly generate a restricted range of cell phenotypes. 
Induced pluripotent stem cells (iPS) have been recently proposed for autologous transplantation, but a major drawback of these genetically manipulated cells is the high risk of cancer formation, mainly due to the uncontrolled integration of retroviral vectors and recombination events.

Therefore, the most feasible candidates to clinical neurological applications are currently the embryonic stem cells (ESCs) and adult somatic stem cells, particularly NSCs.

ESCs are the most primitive type of stem cells properly belonging to the human body and are pluripotent, meaning that they are able to generate all the types of cells present in the human body. As such and thanks to their easy handling and proliferation ex vivo, they would represent ideal candidates to provide a wide array of cell types for the therapy of different disorders. Alas, the limited availability of primary tissue due to ethical concerns and their remarkable teratogenic potential in vivo has strongly discouraged their application in clinical trials. On the contrary, NSC are mostly considered as the optimal cell type for cellmediated therapy of neural disorders because they share the same tissue origin of the damaged cells they are meant to replenish and are amenable to local environmental cues able to commit their differentiation choice (Cao et al. 2001;Shihabuddin et al. 2000;Suhonen et al. 1996). Accordingly, NSC have been shown to exert multiple therapeutic effects, such as secretion of neurotrophic factors and cytokines, scavenging of toxic molecules, immunomodulation of inflammatory milieu, where neural cell replacement plays only a minor role in the recovery of CNS damage (Bacigaluppi et al. 2009;Behrstock et al. 2006;Ebert et al. 2008;Lindvall and Kokaia 2010). The major roadblock to their procurement from an autologous tissue source can be currently circumvented by their derivation from the fetal human brain, while the requirement for immunosuppression to prevent transplant rejection remains object of conflicting debates.

Above all the disavantages of using immunosuppressive treatment during stem cells therapies include an increased risk for opportunistic infections (Garrido et al. 2006), toxic side effects (Rezzani 2006) and potential negative effects on donor cells as recently described (Guo et al. 2007) for cyclosporin treatment able to reduce cell proliferation and affect differentiation of rat NSCs in vitro.

In this manuscript we will discuss about NSC immunogenic potential and the exploitation of -mild- and/or transient immune suppressive protocols after NSC transplantation.

\section{Neural stem cells}

Somatic adult NSCs are undifferentiated cells that reside in specialized regions, namely the niche, of the fetal and adult CNS; they possess life-long self-renewal ability and a multipotent differentiation potential, given their ability to generate neurons, astrocytes and oligodendrocytes. Reynolds and Weiss (Reynolds and Weiss 1992) have first demonstrated a stem cell niche in the CNS. In particular, the finding of adult neurogenesis in the SVZ, which leads to the generation of neural progenitors migrating to the olfactory bulbs and to the cortex, has favoured the idea that newborn neurons might subserve cognitive functions and contribute to the homeostasis of the telencephalic-diencephalic area.

Therefore, NSCs maintain the functional and structural integrity of the brain in physiological conditions, thus contributing to tissue homeostasis and repair throughout adulthood (Gage et al. 1998;Reynolds and Weiss 1992;Temple and Alvarez-Buylla 1999). Alas, given the inherent resilience of NSC to rapidly expand into the adult CNS, there is limited spontaneous recovery after brain damage (Popa-Wagner et al. 2009;Romanko et al. 
2004), so the integration of new functional neurons following injury can be achieved by transplanting exogenous cells. In vitro, NSCs can be propagated as free-floating aggregates called neurospheres or as a cell monolayer (on adhesion) and demonstrate the same characteristics of self-renewal and potential to differentiate into functionally mature neural cells. The establishment of protocols to isolate and culture NSC as stable cell lines able to maintain unaltered their functional properties over passaging ex vivo, has allowed to set up important model systems for studying neurogenic processes during development and neurobiological mechanisms for maintaining cellular complexity and plasticity. Moreover, compelling evidence from transplantation experiments in animal models suggested the potential use of NSC lines in novel cell-based therapies for brain injury and neurodegenerative disease. Interesting, functional recovery by NSC transplantation was mostly reached through alternative mechanisms rather than cell replacement (Pluchino et al. 2005). These mechanisms include neuroprotection and reduction of host cell death (Chu et al. 2004), enhancement of endogenous angiogenesis after stroke (Jiang et al. 2005), immunomodulatory effects on inflammatory damage (Pluchino, et al. 2005;Rota Nodari et al. 2010;Ziv et al. 2006a) and scavenging of neurotoxic molecules (Emsley et al. 2004).

Thus far, cells with stem-like properties have been identified in the mammalian CNS, including that of humans, throughout development and adulthood (Alvarez-Buylla et al. 2001;Gage 2000;Temple 2001). In particular, NSCs have been derived from germinative zones of the brain such as the hippocampal dentate gyrus, olfactory bulb, subventricular zone, subcallosal zone and spinal cord of embryonic, neonatal, and adult rodents (Gritti et al. 1996;Reynolds and Weiss 1992;Weiss et al. 1996). The SVZ has the greatest potential for neurogenesis and is one of the best characterized niches in the adult brain (Doetsch 2003). It consists of a cell layer adjacent to the ependymal layer which lines the lateral ventricles and contains three major cell types. The stem-like cells (type B cells ) have an astroglial phenotype express the glial-fibrillary acidic protein (GFAP), are slow-proliferating but endowed of long-term self-renewal ability (Alvarez-Buylla and Garcia-Verdugo 2002). They give rise to transiently amplifying progenitor cells (type $\mathrm{C}$ cells) which are typically GFAPand express at meaning levels distal-less homeobox 2 (Dlx2) and Epidermal Growth Factor Receptor (EGFR) genes (Pastrana et al. 2009). These type C cells can, in turn, originate migrating neuroblasts (type A cells) which acquire the expression of polisyalylated form of neural cell adhesion molecule (PSA-NCAM) and of doublecortin (Dcx) and migrate to the olfactory bulbs through the a physiological pathway named -rostral migratory stream(RMS). Altogether these cell characteristics suggest that NSCs are the best candidate in advanced therapies on neurodegenerative/inflammatory diseases. Indeed in the last decade NSC were used to putative treatment in a number of different diseases.

\section{Therapeutic potential of NSC}

\subsection{NSCs: Therapy, proof of concept}

Experimentation with intracerebral transplantation of NSCs into animal models has helped to individuate strategies to develop pharmacological and cell replacement therapies for different neurodegenerative pathologies (Anderson et al. 2001), including both genetic diseases like metachromatic leukodystrophy, Huntington's disease and sporadic Alzheimer's disease (AD), and idiopathic diseases like Parkinson's disease (PD), multiple sclerosis (MS), amyotrophic lateral sclerosis (ALS), and stroke (Kim and de Vellis 2009).

In particular, Pluchino et al. recently showed that following intravenous or intracerebral injection in mice affected by an experimental form of MS (EAE), fetal hNSCs can selectively 
reach brain and spinal cord areas affected by the demyelinating-inflammatory process and contribute to myelin restoration and reduction of astrogliosis in those damaged areas (Pluchino et al. 2009;Pluchino et al. 2003). However, a crucial step toward successful clinical application of NSC-mediated therapy is to unravel how immunocompetent in vitro expanded hNSCs are, whether they are amenable to host rejection following transplantation, and whether they present immunomodulatory besides neuroprotective effects after nervous system lesions. The major disadvantage of immune suppression is to excessively undermine the immunity of the patient and the ensuing enhancement of sensitiveness to multiple infections. For a long time a widely held view was that whatever immune activity in the brain was detrimental to the neuronal tissue. However recent studies have elucidated a neuroprotectant role of immune response on neural repair, which basically relies on the mutual interaction between infiltrating blood-immune cells, microglia and neuronal cells, namely a cross-play of regenerative signals generated by the "neurovascular niche" (Madri 2009). Indeed it has been recently shown that both traumatic injury and chronic neurodegeneration induce the activation of resident microglia and infiltration of T-cells and macrophages from the blood vessels, which can exert evident beneficial besides detrimental effects on the surrounding neural tissue (Beers et al. 2006; Glezer et al. 2007;Neumann et al. 2006;Schwartz and Moalem 2001;Ziv, et al. 2006a;Ziv et al. 2006b). These results in combination with unsuccessful clinical studies (in some cases leading to an exacerbation of the disease) radically revised the theory of immune suppression as a therapeutic approach for neurodegenerative disorders. Moreover, the use of immune suppression in order to prevent the rejection of donor NSC transplants can block the immune mediated guidance cues required for the "homing" of NSC to the lesion sites (Ben-Hur 2008). In particular, Fibroblast Growth Factor 2 (FGF2) (Craig et al. 1996;Kuhn et al. 1997), tumor necrosis factora (TNF- $\alpha$ ) and Interferon- $\gamma$ (IFN- $\gamma$ ) have been shown to induce cell mobilization (Ben-Hur et al. 2003), while other cytokines drive NSC migration to the lesion through specific physiological pathways, such as the monocyte chemoattractant protein-1 (MCP-1) (Belmadani et al. 2006), hepatocyte growth factor (HGF) (Lalive et al. 2005), Epidermal Growth Factor (EGF), platelet Growth Factor (PDGF) (Armstrong et al. 1990), and stromal derived growth factor (SDF-1 or CXCL12) (Imitola et al. 2004b).

Interestingly, the majority of hNSC lines expanded in vitro display low dissimilitaries in the major histocompatibility complex (MHC) expression pattern, most likely owing to different culture conditions and to the origin of the primary tissue.

The presence of MHC class I and II molecules on human NSC isolated by our group (Figure 1), or described by Akesson and colleagues (Akesson et al. 2009) would presumably predict a risk for rejection after transplantation. However, Akesson demonstrated that neither NSCs nor differentiated cells were recognized by alloreactive lymphocytes.. Indeed, human NSCs and newly formed astrocytes, but not neurons, suppressed lymphocyte stimulation to alloantigens, suggesting low risk for alloreaction and a role as immunomodulators. Despite these results, in accordance with providing evidence of NSCs low immunogenicity (Odeberg et al. 2005) and ability to produce TGF- $\beta$ cytokine with a potent bystander effect on limpho/monocytes (Ubiali et al. 2007), the presence of MHC class I and II molecules on hNSCs implies a risk for recognition by alloreactive $\mathrm{T}$ cells after transplantation, thus indicating a potential risk for immunological rejection due to MHC incompatibility and subsequent requirement of immunosuppressive treatment to avoid rejection.

The disadvantages of using immunosuppressive treatment include an increased risk for opportunistic infections, toxic side effects and potential negative effects on donor cells. 
Notwithstanding several clinical trials harnessing various sources of neural stem cells such as ESC-derived progenitors, spinal cord NSC and fetal NSC are currently ongoing (www.clinicaltrials.org).
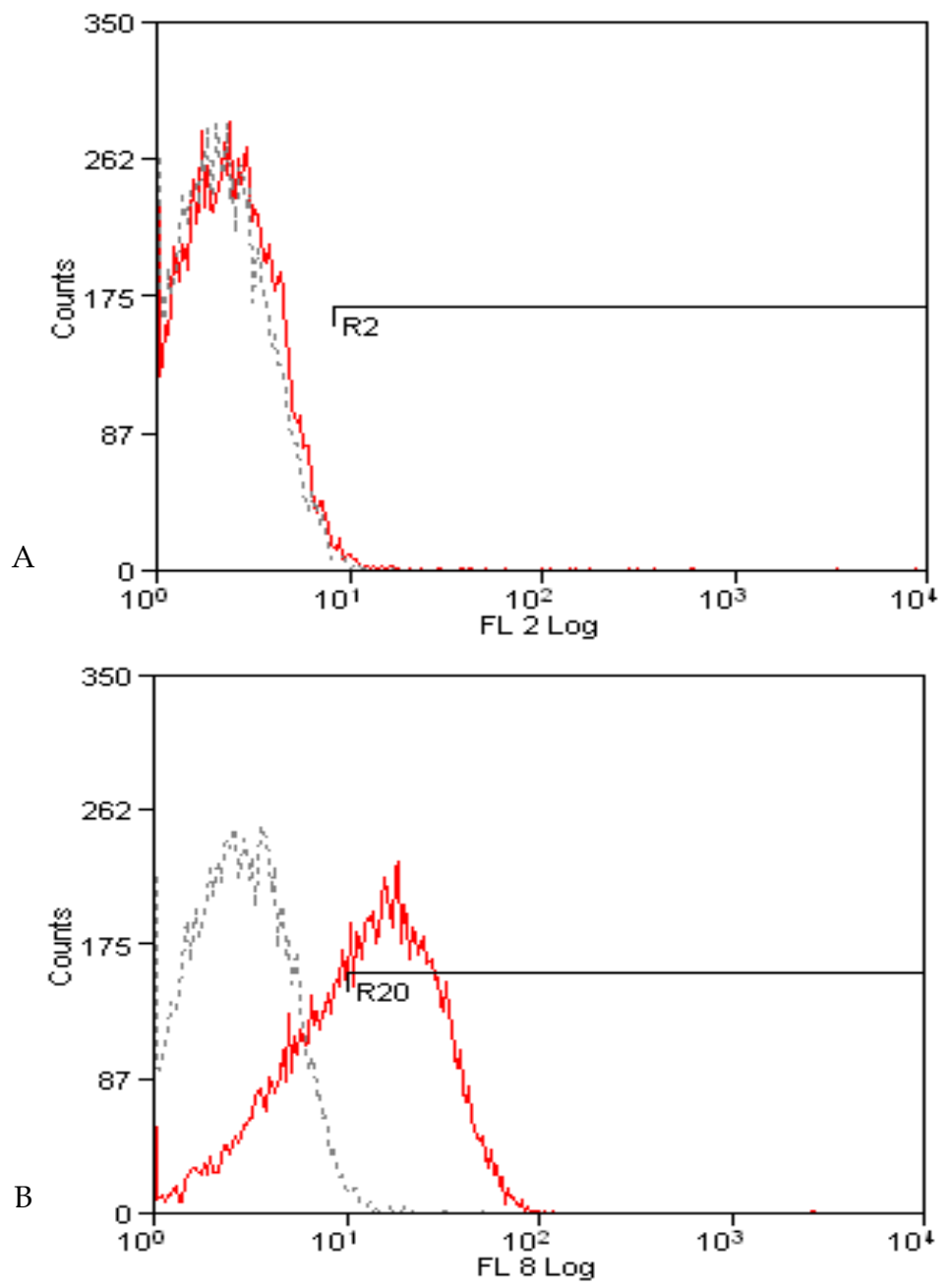

Fig. 1. Cytofluorimetric analysis of HLA class I and II on cultured human neural stem cells (hNSC). A) absence of HLA DR (Class II) on hNSC cell surface. B) Expression of HLA ABC (Class I) on hNSC cell surface

\section{Establishment of human NSC lines for clinical application}

\subsection{NSCs: Cells "clinical grade" produced under GMPs guidelines}

Our hNSCs have now been serially expanded under chemically defined conditions and are being cryopreserved, establishing a Good Manufacturing Practice (GMP)-grade, hNSCs 
bank. In order to certify these cells by the GMP standard, a panel of cellular, functional and biochemical criteria must be met prior to cell release, which include, but are not limited to, karyotype analysis, stable differentiation and growth capacity, and lack of biological contamination by adventitious agents.

In our GMP facility designed to produce human neural stem cells for advanced therapies, quality control is only part of overall quality assurance for cell lines which includes: evaluation and quality control measures for cells and critical reagents coming into the laboratory, control of the laboratory environment, equipment and procedures, control of data arising from cell culture, control of the delivery of research materials, including cells, to other laboratories and traceability of raw material, especially tissue from donors.

Four critical characteristics of cell cultures are fundamental to assure the quality of cell culture work:

1. Identity, i.e., the cells need to possess a specific behaviour:

i. Self Renewal: growth kinetic stable for a elevated number of passages in vitro

ii. Multipotency: NSCs are able to differentiate into 3 neural lineages (Astrocytes, Neuron and oligodendrocytes) after growth factors (EGF and bFGF) removal

2. Purity, i.e., freedom from microbiological contamination (all the assays need to be performed according to official Europeian Pharmacopeia, current edition)

i. Sterility (Bacteria and fungi)

ii. Mycoplasma

iii. Bacterial Endotoxins

iv. Viral contamination

v. BSE (at least a risk analysis)

3. Maintenance of stable functional properties over passaging in vitro

i. Growth curve: constant positive slope over passages

ii. Constant ratio neurons/astrocytes/oligodendrocytes upon differentiation assay

iii. Karyology (healthy karyotype asset and deeper analysis like SKY or comparative genomic hybridisation)

4. Tumorigenicity, i.e., Cell lines not toxic or tumorigenic

i. Growth factor dependence: the cells died into a few passages after EGF and bFGF removal from culture medium.

ii. No tumor signs after transplantation into the brain of Nude mice (Figure 2). The cells are able to migrate, differentiate and integrate into host tissue.

Because all of the characteristics above mentioned, raw material (media, cell culture plastic disposable, etc.) were obtained from GMP certified suppliers. Human Neural Stem Cells were produced into controlled environment (class A surrounded by Class B) according to Annex I Vol.4 European GMP Guidelines. Tissue samples were obtained from screened donors according to European Guidelines on "Certain technical requirements for the donation, procurement and testing of human tissues and cell" (Implementing Directive 2004/23/EC of the European Parliament and of the Council).

\section{Current immunosuppression in transplant}

\subsection{Immunosuppressive drugs in cells transplant}

Immunosuppression after transplantations is complex and improved therapeutic strategies have contributed to ameliorate the quality of the patient's life and to enhance the survival of the graft; however, the adverse effects associated with immunosuppressive compounds and 

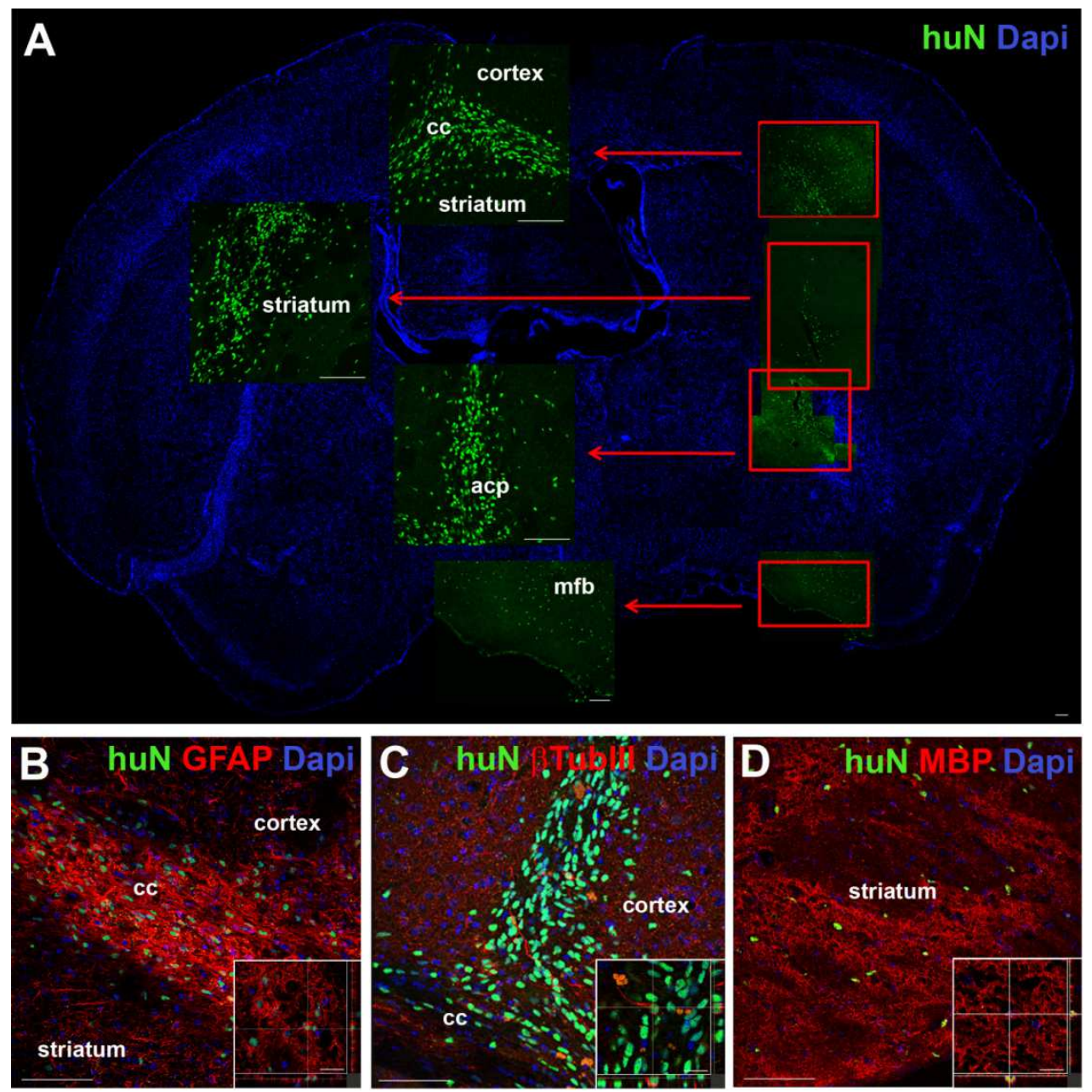

Fig. 2. Panel A-D) Nude mice were injected in striatum with hNSCs. Six months after transplantation mice with hNSCs were sacrificed and immunohistochemistry analysis showed that hNSCs engraft efficiently and migrate throughout the injected hemisphere. (A) Brain map showing the localization of huN+ cells the cells colonized cortex, cc, striatum, acp and $\mathrm{mfb}$. B-D Confocal microscopy analysis showing integration and differentiation of hNSC at 6 months from transplantation into the striatum of nude mice. A) migration of gfpTransduced hNSC along the corpus callosum and to the striatum of the ipsilateral emisphere. B-D) expression of differentiation and proliferation markers by hNSC identified as human-Nuclei (huN)-immunoreactive cells. Immunostaining with the astroglial marker Glial Fibrillary Acidic Protein (GFAP, B), the neuronal protein $\beta$-TubulinIII (C) and the late oligodendroglial marker Myelin Basic Protein (MBP, D). Insets show huN+/MBP colocalization. Nuclei are shown by dapi staining (blue). Scale bars: in $A=100 \mu \mathrm{m}$; in B$\mathrm{D}=75 \mu \mathrm{m}$ inset scale bar: $\mathrm{B}-\mathrm{D}=12-17 \mu \mathrm{m}$. apc: posterior part of anterior commissure; cc: corpus callosum; $\mathrm{mfb}=$ medial forebrain bundle 


\begin{tabular}{|c|c|c|c|}
\hline DRUG & & MECHANISM OF ACTION & EFFECTS \\
\hline Cyclosporine & Calcineurin inhibitor & $\begin{array}{l}\text { Binding to the cytosolic protein cyclophilin of } \\
\text { immunocompetent lymphocytes and preventing } \\
\text { the production of IL-2. }\end{array}$ & $\begin{array}{l}\text { Induction and mainteinance of } \\
\text { immunosuppression }\end{array}$ \\
\hline Tacrolimus (FK-506) & $\begin{array}{l}\text { Macrolide antibiotic } \\
\text { (calcineurin inhibitor) }\end{array}$ & $\begin{array}{l}\text { Reducing peptidyl-prolyl isomerase activity by } \\
\text { binding to the immunophilin FKBP12 and } \\
\text { creating a new complex FKBP12-FK506 which } \\
\text { inhibits both T-lymphocyte signal transduction } \\
\text { and IL-2 transcription. }\end{array}$ & $\begin{array}{l}\text { Maintenance } \\
\text { immunosuppression and for } \\
\text { rescue therapy in patients with } \\
\text { refractory rejection under } \\
\text { cyclosporine based therapy } \\
\end{array}$ \\
\hline Sirolimus (Rapamycin) & Macrolide & $\begin{array}{l}\text { Binding the cytosolic protein FK-binding protein } \\
12 \text { and inhibiting the response to IL-2 and the } \\
\text { activation of T and B-cells. }\end{array}$ & $\begin{array}{l}\text { Maintenance } \\
\text { immunosuppression and } \\
\text { protection from chronic } \\
\text { rejection }\end{array}$ \\
\hline $\begin{array}{l}\text { Mycophenolate mofetil } \\
\text { (MMF) }\end{array}$ & $\begin{array}{l}\text { IProdrug of Mycophenolic } \\
\text { Acid }\end{array}$ & $\begin{array}{l}\text { Inhibiting inosine monophoshate } \\
\text { dehydrogenase impairing B and T-cells } \\
\text { proliferation. }\end{array}$ & $\begin{array}{l}\text { Maintenance } \\
\text { immunosuppression and } \\
\text { protection from chronic } \\
\text { rejection }\end{array}$ \\
\hline Azathiopine & Purine analogue & $\begin{array}{l}\text { Decreasing DNA and RNA synthesis and } \\
\text { inhibiting the proliferation of fast-growing } \\
\text { lymphocytes (T and B-cells particulary) }\end{array}$ & $\begin{array}{l}\text { Maintenance } \\
\text { immunosuppression }\end{array}$ \\
\hline Corticosteroids & Steroids hormones & $\begin{array}{l}\text { Preventing interleukin IL-1 and IL- } 6 \text { production } \\
\text { by macrophages and inhibiting all stages of T- } \\
\text { cells activation }\end{array}$ & $\begin{array}{l}\text { Induction, maintenance } \\
\text { immunosuppression and } \\
\text { protection from acute rejections }\end{array}$ \\
\hline Muromonab-CD3 (OKT-3) & $\begin{array}{l}\text { Monoclonal Antibody of } \\
\operatorname{IgG}_{2 \mathrm{~A}} \text { clones to the CD3 } \\
\text { portion of the T-cell } \\
\text { recepto }\end{array}$ & Blocking T-cell function & $\begin{array}{l}\text { Induction of } \\
\text { immunosuppression and } \\
\text { protection from acute rejection } \\
\text { (primary treatment or steroid- } \\
\text { resistant) }\end{array}$ \\
\hline
\end{tabular}


the risks of inducing a long-term immunosuppression represent a challenging issue for researches and clinicians. Total body radiation after organs' transplantation was among the first protocols of immunosuppression, but it resulted as extremely severe and led inexorably to the death of all the patients. Therefore, steroid alone were used without success. With the development of 6-mercaptopurine (Purinethol), followed by azathioprine (Imuran) in the 1960s, pharmacological immunosuppression became the standard protocol after both organs and cells transplantation until 1980s, when cyclosporine (Sandimmune and Neoral) was introduced as the first calcineurin inhibitor. Calcineurin is a protein phosphatase also known as protein phosphatase 3, PPP3CA, which activates the T cells of the immune system and can be blocked by drugs. Cyclosporine was initially used in combination with azathioprine and steroids and was credited with a dramatic improvement of graft survival. Cyclosporin is thought to bind to the cytosolic protein cyclophilin (an immunophilin) of immunocompetent lymphocytes, especially T-lymphocytes. This complex of ciclosporin and cyclophilin inhibits the phosphatase calcineurin, which under baseline conditions induces the transcription of interleukin-2. The drugs also inhibits lymphokine production and interleukin release, leading to a reduced function of effector T-cells. In 1994 another calcineurin inhibitor, the macrolide antibiotic Tacrolimus (or FK-506), active against helper T cells, became available and gradually supplanted cyclosporine in many clinical Institutes. It has been largely used for maintenance of the immunosuppression and for rescue therapy in patients with refractory rejection under cyclosporine-based therapy. However, the risk of both acute and chronic nephrotoxicity attributed to calcineurin inhibitors has strongly suggested the development of protocols free of these agents as most desirable.

At the present, numerous immunosuppressive drugs and protocols have been designed for transplantation (Table 1), but a protocol which is highly effective with minimal side effects has still to be identified. In this view, although the brain is commonly considered partially "immunoprivileged", a specific immunosuppression regimen has to provide the best conditions allowing graft survival, preventing the patient from the additional burden of an immune reaction against the graft (Barker and Widner 2004).

Actually, the precise sequelae of events leading from antigen recognition to lymphocyte activation and proliferation has still to be elucidated. However, recent findings, concerning the molecular actions of cyclosporine A (CsA) and the new immunosuppressive drugs, Tacrolimus and Rapamycin, have provided important novel breakthroughs in the biochemical processes involved. Interestingly, none of the T-cell directed immunosuppressants is, by itself, anti-lymphocyitic. Conversely, these molecules act as "molecular adaptors" which mediate the interaction between specific intracellular drugbinding proteins and target molecules. Several additional drugs are currently used as immunomodulatory agents, eventually in combination with Calcinneurin inhibitors. Most of these, like steroids, azathioprine, MMF, sirolimus, are routinely used in peripheral organ allograft programs with a unique and different mode of action to that of tacrolimus and cyclosporin A (Table1). The use of adjuvants agents allows clinicians to achieve adequate immunosuppression while decreasing the dose and the toxicity of individual agents.

In neural transplantation, immunomodulators have been used experimentally, in particular with xenografts. Antibodies against T-cell receptor anti-TCR and T cells have been used to enhance the survival of intracerebral neural xenografts in rats (Okura et al. 1997; Wood et al. 1996). Also the use of blockers of T-cells costimulatory molecules have been explored as alternative route to tolerance, therefore highlighting the value of targeting this arm of the immune response for xenograft survival (Larsson et al. 2003;Larsson et al. 2002). 


\section{Low immunogenic potential of NSC}

We already obtained some evidence of hNSCs efficacy and immunogenic tolerance upon transplantation into animal models of neurological disorders (Rota Nodari, et al. 2010) such as transient global ischemia, which is a model of vascular dementia and resembles several pathological features of AD. At 3 days from global ischemic injury, hNSC were unilaterally implantated into the corpus callosum or the hippocampal fissure of adult rat brains. After 1 month, hNSCs were detected to migrate through the corpus callosum (Fig.3), into the cortex or throughout the dentate gyrus of the hippocampus and by the fourth month, to reach the ipsilateral subventricular zone, the CA1-3 hippocampal layers and the controlateral hemisphere, showing to be non-tumorigenic and to undergo a proper regional differentiation into GABAergic and GLUTAmatergic neurons (Rota Nodari, et al. 2010). Notably, these results could be accomplished using transient immunosuppression, i.e administering cyclosporine for 15 days following the ischemic event. A wide array of studies have shown that NSCs are not susceptible to immunological rejection (Bjorklund et al. 2003;Mendez et al. 2008;Olstorn et al. 2007;Wennersten et al. 2006) even when transplanted in animal models like EAE, characterized by a constitutively activated immunological response(Pluchino, et al. 2003;Pluchino, et al. 2005). Similar results were also obtained in a different context: after transplantation into the adult rat brain lesioned by focal demyelination (Ferrari et al., submitted), hNSCs demonstrated to integrate into the NSC host niche and to migrate toward the lesioned corpus callosum, where they properly differentiated into myelinating oligodendrocytes. No sign of tumorigenicity was ever

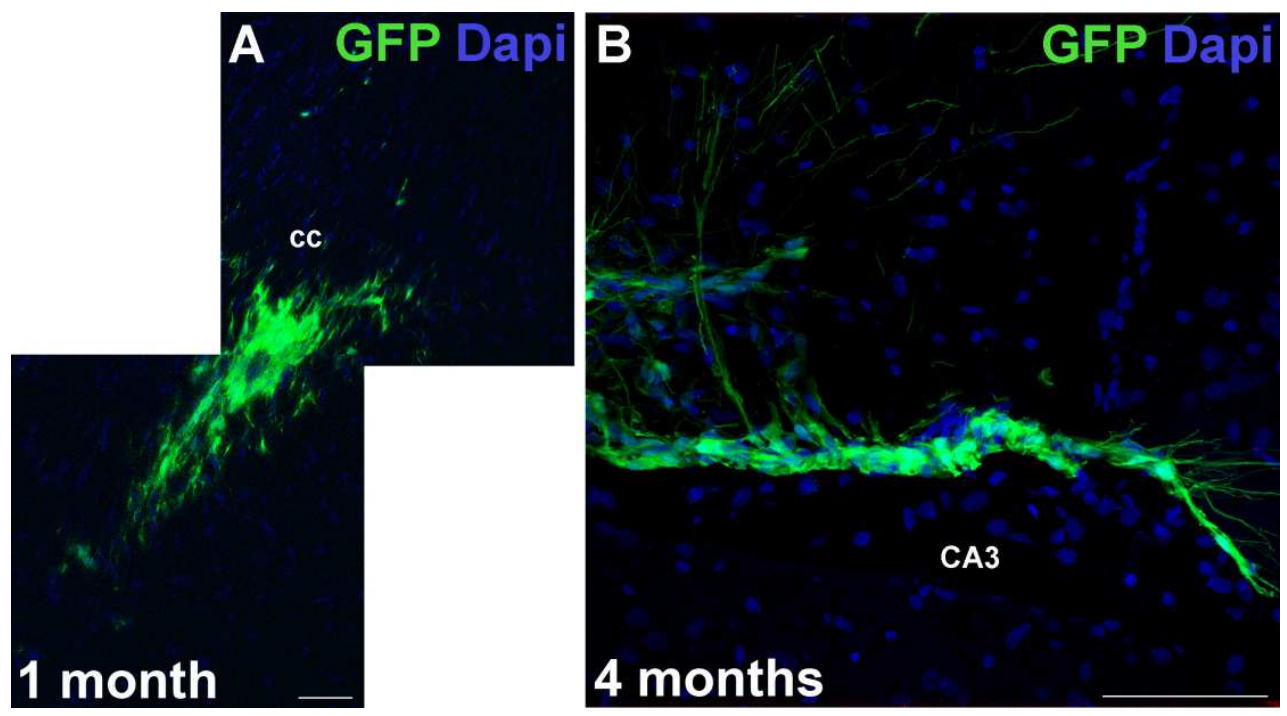

Fig. 3. hNSC transduced with a lentiviral vector carrying the reporter gene gfp were transplanted into the brain of adult rats after 3 days from lesioning by transient global ischemia. Confocal microscopy analysis showing hNSC-GFP integration into the corpus callosum (A) (1 month from transplantation) and in the hippocampal CA3 layer (B) ( 4 months from transplantation) under transient immunosuppression. Total nuclei are shown by dapi staining (blue). Scale Bar: $50 \mu \mathrm{m}$. cc: corpus callosum; CA3: hippocampal layer 
detected upon transplantation of hNSCs (unpublished observation) nor of hNSC immortalized with proliferating genes as c-myc, c-myc T58A and v-myc (De Filippis et al. 2008; De Filippis et al. 2007). These results have confirmed that hNSC are scarcely immunogenic. Consistently, parallel analysis of hNSC in vitro by cytofluorimetric assays showed that hNSC display only a very faint expression of HLA DR compared to a normal expression of HLA A, B and C (see Figure 1). Moreover, recent studies have shown that hNSCs may also exert their therapeutic potential through an immunomodulatory action (Bacigaluppi, et al. 2009; Pluchino, et al. 2009; Pluchino, et al. 2005).

\section{NSC-mediated immunomodulation of the inflammatory component in neurodegenerative disorders}

Besides neurodegeneration per se, one of the hallmarks characterizing most neurodegenerative disorders like stroke, AD, PD, ALS, MLD, is the development of an inflammatory environment, which can contribute to tissue damage (Glass et al. 2010). Although for a long time the NSC-mediated therapy was basically aimed at replacing damaged neural cells (Lindvall et al. 2004; Pluchino, et al. 2003), the local immune response has been shown to play a key role in recruitment of neural precursors to the lesion site. When neuroinflammation is prevailing over neurodegeneration, NSC have been shown to promote long-lasting neuroprotection and to exert unexpected immune-like functions (Pluchino, et al. 2005). Pluchino et al. (Pluchino, et al. 2005) showed that after systemic injection into a mouse model of multiple sclerosis, transplanted NSC are recruited into perivascular niche areas, where they retain undifferentiated features, proliferate and promote CNS repair through a cross-talk with inflammatory CNS-infiltrating T cells. A dual role in the regulation of both neurogenesis and oligodendrogenesis of adult neural progenitor cells is played by microglia (Streit 2002), so that the two physiological processes can be blocked by inflammationassociated microglia or induced by IL-4/IFN- $\gamma$ associated to T-helper cells (Butovsky et al. 2006). Several studies have demonstrated that $T$ cells able to recognize CNS antigens can foster spontaneous recovery from CNS injuries through an active cross-talk with local microglia (Hauben et al. 2000;Hofstetter et al. 2003;Moalem et al. 1999; Yoles et al. 2001). Consistently, T cell-based vaccination of mice with a myelin-derived peptide appeared to synergistically promote functional recovery after spinal cord injury when combined with transplantation of neural precursors into the cerebro-spinal fluid (Ziv, et al. 2006a). It's important to consider that immune cells are involved in the control of neurogenesis even under physiological conditions (Ziv, et al. 2006b). However, under pathological environment, the outcome of the interplay between inflammation, synaptic transmission and neurodegeneration is strongly conditioned by the short- or long-term persistence of inflammation (Centonze et al. 2010;Pluchino et al. 2008). Upon acute inflammatory injuries, such as stroke, neurogenesis is notably increased (Zhang et al. 2004). Conversely, a persistent brain inflammation in chronic inflammatory disorders, such as MS (Pluchino, et al. 2008) has been shown to alter both the proliferative and migratory capacities of NSCs in the SVZ, thus leading to a perpetuating non cell-autonomous dysfunction of the endogenous CNS stem cell compartment.

Both in the globally ischemic and focally demyelinated rat brains, we observed that transplantation of hNSCs can effectively decrease reactive astrogliosis and dampen microglial activation in the injuried areas (Rota Nodari, et al. 2010); unpublished results).

This phenomenon may, in fact, participate in the low immunogenic response that these cells seem to elicit in the CNS, together with the lack of expression of Molecular 
Histocompatibility Complex class II components (MHCII) (Imitola et al. 2004a;Imitola, et al. 2004b)(see also Fig 1). Notwithstanding, it is also true that some level of immune surveillance is maintained in the adult brain upon NSC engraftment, which explains the widespread need to use immune suppression (Wennersten, et al. 2006) in experimental and clinical intracerebral transplantation (Bjorklund, et al. 2003;Olstorn, et al. 2007).The successful use of transient immunosuppression proposes a suitable milder approach to immunosuppression for the prospective use of hNSCs for clinical purposes. The fact that the discontinuous treatment with cyclosporine does not affect integration of transplanted cells in most of the brain regions, which to all effects emerge as immunoprivileged when considering hNSCs, is in good accordance with most recent findings (Wennersten, et al. 2006). These evidences are driving the progressive translation of the knowledge "from the bench to the bedside", thus leading to the use of hNSCs as a suitable tool to model transplantation in pre-clinical settings and to the promotion of GMP-grade hNSC for stem cell-mediated therapy of neurodegenerative disorders.

\section{Transplanted NSC switch on or off the immune reactivity into host?}

Usually, after the cell or tissue transplant into CNS, the intensity and rapidity of the rejection depend on the phylogenetic distance between donor and host (Dymecki et al. 1990;Mason et al. 1986;Pakzaban and Isacson 1994) and the status of the host immune system (Marion et al. 1990), but also from the nature and differentiation state of transplanted cells. Capetian and colleagues (Capetian et al. 2011) demonstrate that murine NSCs derived from newborn C57BL/6, cultured as neurospheres and placed into kidney capsule as a nonimmunopriviliged site of BALB/c survived for 28 days without rejection although these 2 strains were been immunologically incompatible. However the graft were readly rejected when the recipient animal was either pre or post sensitized using donor splenocytes.

Also in these example, as well as in our human cells (Figure 1) the murine neural stem cells showed no expression of MHC I or II, in contrast with surrounding tissue or other terminally differentiated cells. This demonstrated that NSCs themselves are not attacked by immune defense mechanisms since they do not sensitize host (so they have a low immunogenicity), but can however be rejected if the host is or becomes sensitized.

In the past there have been concerns that the loss or lack of clinical improvement after neural grafting could be due to immunological rejection processes that compromise neural graft survival and function. However, autopsy findings of patients at long-term follow-up post-transplantation showed little evidence of immunological reactions (Freeman et al. 2000;Kordower et al. 2008;Kordower et al. 1996; Li et al. 2008;Mendez et al. 2005).

According to results of different clinical trials on Huntington Disease where all the patients received adequate immunosuppression for over 1 year, most of the patients developed anti HLA I antibodies but only few showed overt signs of immunological rejection.

Moreover there are accruing evidences (Pluchino, et al. 2009) that NSCs injected into CNS or intravenously in multiple sclerosis animal models are scarcely (if any) prone to differentiate, while they are able to exert a plethora of "healing actions", such as production of pleiotropic factors and cytokines, scavenging of toxic molecules and immunomodulation of the inflammatory environment. In addition Akesson and colleagues (Akesson, et al. 2009) have shown that human Neural stem cells derived from aborted fetuses of 5-12 weeks of gestation were able to inhibit lymphocyte proliferation induced by alloantigen and at NSC:Lymphomonocyte ratio of 1:1 a complete suppression was seen. These effect was 
clearly specific and mediated by cell-cell interactions as demonstrated by tha fact that the above mentioned proliferation was not affected by presence or absence of supernatants from NSCs cultures.

Moreover, recent evidence has suggested that the majority of the stem cell-mediated therapeutic effects in inflammatory CNS disorders are possibly taking place peripherally, at the level of immune relevant anatomical site, such as secondary lymphoid organs.

On the other hand the surgery could influence "per se" the fate of transplanted cells, albeit stereotactic techniques allow to inject NSCs by a minimally invasive procedure.

There are three main factors to be taken in account that can influence the extent of the host reaction and graft survival in an intraparenchimal cell graft: i) the extent of tissue trauma during injection, ii) cell suspension preparation and iii) the site of implantation.

The intraparenchymal injection lead to breakage of blood brain barrier at least for a couple of weeks facilitating the limphomonocyte patrolling and reaction against the graft. A low viability of cell suspensions could also trigger an immune reaction. Furthermore, the site of implantation can have a considerable effect on the host immune reaction. For example, perior intraventricular graft placement can lead to increased rates of immune response in terms of MHC class I expression inside the grafts and lymphocyte invasion (Oertel et al. 2004).

\section{Conclusions}

Although NSCs cell therapy seem to be a promising development for a number on neurological diseases, transplantation of NSC into the central nervous system is from an immunological viewpoint a true challenge both for the host as well as for the donor cells. Moreover more experiments are necessary to fully elucidate the mechanisms underlining the interactions between stem cells graft and host immune system. In conclusion, the mildest approach for clinical trials on humans is likely a transient immunosuppression regimen.

\section{Acknowledgements}

We thank Cristina Zalfa for image editing, Giuseppe Lamorte for FACS analysis and Prof. Angelo Vescovi for precious suggestions. This work was supported by Fondazione Borgonovo, Fondazione Neurothon ONLUS, Fondazione Cellule Staminali of Terni, Fondazione Milan.

\section{References}

Akesson E, Wolmer-Solberg N, Cederarv M, Falci S and Odeberg J. 2009. Human neural stem cells and astrocytes, but not neurons, suppress an allogeneic lymphocyte response. Stem Cell Res 2(1):56-67.

Alvarez-Buylla A and Garcia-Verdugo JM. 2002. Neurogenesis in adult subventricular zone. J Neurosci 22(3):629-34.

Alvarez-Buylla A, Garcia-Verdugo JM and Tramontin AD. 2001. A unified hypothesis on the lineage of neural stem cells. Nat Rev Neurosci 2(4):287-93.

Anderson DJ, Gage FH and Weissman IL. 2001. Can stem cells cross lineage boundaries? Nat Med 7(4):393-5.

Armstrong RC, Harvath L and Dubois-Dalcq ME. 1990. Type 1 astrocytes and oligodendrocyte-type 2 astrocyte glial progenitors migrate toward distinct molecules. J Neurosci Res 27(3):400-7. 
Bacigaluppi M, Pluchino S, Peruzzotti Jametti L, Kilic E, Kilic U, Salani G, Brambilla E, West MJ, Comi G, Martino Gand others. 2009. Delayed post-ischaemic neuroprotection following systemic neural stem cell transplantation involves multiple mechanisms. Brain 132(Pt 8):2239-51.

Barker RA and Widner H. 2004. Immune problems in central nervous system cell therapy. NeuroRx 1(4):472-81.

Beers DR, Henkel JS, Xiao Q, Zhao W, Wang J, Yen AA, Siklos L, McKercher SR and Appel SH. 2006. Wild-type microglia extend survival in PU.1 knockout mice with familial amyotrophic lateral sclerosis. Proc Natl Acad Sci U S A 103(43):16021-6.

Behrstock S, Ebert A, McHugh J, Vosberg S, Moore J, Schneider B, Capowski E, Hei D, Kordower J, Aebischer Pand others. 2006. Human neural progenitors deliver glial cell line-derived neurotrophic factor to parkinsonian rodents and aged primates. Gene Ther 13(5):379-88.

Belmadani A, Tran PB, Ren D and Miller RJ. 2006. Chemokines regulate the migration of neural progenitors to sites of neuroinflammation. J Neurosci 26(12):3182-91.

Ben-Hur T. 2008. Immunomodulation by neural stem cells. J Neurol Sci 265(1-2):102-4.

Ben-Hur T, Ben-Menachem O, Furer V, Einstein O, Mizrachi-Kol R and Grigoriadis N. 2003. Effects of proinflammatory cytokines on the growth, fate, and motility of multipotential neural precursor cells. Mol Cell Neurosci 24(3):623-31.

Bjorklund A, Dunnett SB, Brundin P, Stoessl AJ, Freed CR, Breeze RE, Levivier M, Peschanski M, Studer L and Barker R. 2003. Neural transplantation for the treatment of Parkinson's disease. Lancet Neurol 2(7):437-45.

Butovsky O, Ziv Y, Schwartz A, Landa G, Talpalar AE, Pluchino S, Martino G and Schwartz M. 2006. Microglia activated by IL-4 or IFN-gamma differentially induce neurogenesis and oligodendrogenesis from adult stem/progenitor cells. Mol Cell Neurosci 31(1):149-60.

Cao QL, Zhang YP, Howard RM, Walters WM, Tsoulfas P and Whittemore SR. 2001. Pluripotent stem cells engrafted into the normal or lesioned adult rat spinal cord are restricted to a glial lineage. Exp Neurol 167(1):48-58.

Capetian P, Dobrossy M, Winkler C, Prinz M and Nikkhah G. 2011. To be or not to be accepted: the role of immunogenicity of neural stem cells following transplantation into the brain in animal and human studies. Semin Immunopathol.

Centonze D, Muzio L, Rossi S, Furlan R, Bernardi G and Martino G. 2010. The link between inflammation, synaptic transmission and neurodegeneration in multiple sclerosis. Cell Death Differ 17(7):1083-91.

Chu K, Kim M, Park KI, Jeong SW, Park HK, Jung KH, Lee ST, Kang L, Lee K, Park DKand others. 2004. Human neural stem cells improve sensorimotor deficits in the adult rat brain with experimental focal ischemia. Brain Res 1016(2):145-53.

Craig CG, Tropepe V, Morshead CM, Reynolds BA, Weiss S and van der Kooy D. 1996. In vivo growth factor expansion of endogenous subependymal neural precursor cell populations in the adult mouse brain. J Neurosci 16(8):2649-58.

De Filippis L, Ferrari D, Rota Nodari L, Amati B, Snyder E and Vescovi AL. 2008. Immortalization of human neural stem cells with the c-myc mutant T58A. PLoS One 3(10):e3310.

De Filippis L, Lamorte G, Snyder EY, Malgaroli A and Vescovi AL. 2007. A novel, immortal, and multipotent human neural stem cell line generating functional neurons and oligodendrocytes. Stem Cells 25(9):2312-21. 
Doetsch F. 2003. A niche for adult neural stem cells. Curr Opin Genet Dev 13(5):543-50.

Dymecki J, Poltorak M and Freed WJ. 1990. The degree of genetic disparity between donor and host correlates with survival of intraventricular substantia nigra grafts. Reg Immunol 3(1):17-22.

Ebert AD, Beres AJ, Barber AE and Svendsen CN. 2008. Human neural progenitor cells overexpressing IGF-1 protect dopamine neurons and restore function in a rat model of Parkinson's disease. Exp Neurol 209(1):213-23.

Emsley JG, Mitchell BD, Magavi SS, Arlotta P and Macklis JD. 2004. The repair of complex neuronal circuitry by transplanted and endogenous precursors. NeuroRx 1(4):45271.

Freeman TB, Cicchetti F, Hauser RA, Deacon TW, Li XJ, Hersch SM, Nauert GM, Sanberg PR, Kordower JH, Saporta Sand others. 2000. Transplanted fetal striatum in Huntington's disease: phenotypic development and lack of pathology. Proc Natl Acad Sci U S A 97(25):13877-82.

Gage FH. 2000. Mammalian neural stem cells. Science 287(5457):1433-8.

Gage FH, Kempermann G, Palmer TD, Peterson DA and Ray J. 1998. Multipotent progenitor cells in the adult dentate gyrus. J Neurobiol 36(2):249-66.

Garrido RS, Aguado JM, Diaz-Pedroche C, Len O, Montejo M, Moreno A, Gurgui M, TorreCisneros J, Pareja F, Segovia Jand others. 2006. A review of critical periods for opportunistic infection in the new transplantation era. Transplantation 82(11):145762.

Glass CK, Saijo K, Winner B, Marchetto MC and Gage FH. 2010. Mechanisms underlying inflammation in neurodegeneration. Cell 140(6):918-34.

Glezer I, Simard AR and Rivest S. 2007. Neuroprotective role of the innate immune system by microglia. Neuroscience 147(4):867-83.

Gritti A, Parati EA, Cova L, Frolichsthal P, Galli R, Wanke E, Faravelli L, Morassutti DJ, Roisen F, Nickel DDand others. 1996. Multipotential stem cells from the adult mouse brain proliferate and self-renew in response to basic fibroblast growth factor. J Neurosci 16(3):1091-100.

Guo J, Zeng Y, Liang Y, Wang L, Su H and Wu W. 2007. Cyclosporine affects the proliferation and differentiation of neural stem cells in culture. Neuroreport 18(9):863-8.

Hauben E, Butovsky O, Nevo U, Yoles E, Moalem G, Agranov E, Mor F, Leibowitz-Amit R, Pevsner E, Akselrod Sand others. 2000. Passive or active immunization with myelin basic protein promotes recovery from spinal cord contusion. J Neurosci 20(17):642130.

Hofstetter HH, Sewell DL, Liu F, Sandor M, Forsthuber T, Lehmann PV and Fabry Z. 2003. Autoreactive T cells promote post-traumatic healing in the central nervous system. J Neuroimmunol 134(1-2):25-34.

Imitola J, Comabella M, Chandraker AK, Dangond F, Sayegh MH, Snyder EY and Khoury SJ. 2004a. Neural stem/progenitor cells express costimulatory molecules that are differentially regulated by inflammatory and apoptotic stimuli. Am J Pathol 164(5):1615-25.

Imitola J, Raddassi K, Park KI, Mueller FJ, Nieto M, Teng YD, Frenkel D, Li J, Sidman RL, Walsh CAand others. 2004b. Directed migration of neural stem cells to sites of CNS injury by the stromal cell-derived factor 1alpha/CXC chemokine receptor 4 pathway. Proc Natl Acad Sci U S A 101(52):18117-22. 
Jiang Q, Zhang ZG, Ding GL, Zhang L, Ewing JR, Wang L, Zhang R, Li L, Lu M, Meng Hand others. 2005. Investigation of neural progenitor cell induced angiogenesis after embolic stroke in rat using MRI. Neuroimage 28(3):698-707.

Kim SU and de Vellis J. 2009. Stem cell-based cell therapy in neurological diseases: a review. J Neurosci Res 87(10):2183-200.

Kordower JH, Chu Y, Hauser RA, Freeman TB and Olanow CW. 2008. Lewy body-like pathology in long-term embryonic nigral transplants in Parkinson's disease. Nat Med 14(5):504-6.

Kordower JH, Rosenstein JM, Collier TJ, Burke MA, Chen EY, Li JM, Martel L, Levey AE, Mufson EJ, Freeman TBand others. 1996. Functional fetal nigral grafts in a patient with Parkinson's disease: chemoanatomic, ultrastructural, and metabolic studies. J Comp Neurol 370(2):203-30.

Kuhn HG, Winkler J, Kempermann G, Thal LJ and Gage FH. 1997. Epidermal growth factor and fibroblast growth factor-2 have different effects on neural progenitors in the adult rat brain. J Neurosci 17(15):5820-9.

Lalive PH, Paglinawan R, Biollaz G, Kappos EA, Leone DP, Malipiero U, Relvas JB, Moransard M, Suter T and Fontana A. 2005. TGF-beta-treated microglia induce oligodendrocyte precursor cell chemotaxis through the HGF-c-Met pathway. Eur J Immunol 35(3):727-37.

Larsson LC, Corbascio M, Pearson TC, Larsen CP, Ekberg H and Widner H. 2003. Induction of operational tolerance to discordant dopaminergic porcine xenografts. Transplantation 75(9):1448-54.

Larsson LC, Corbascio M, Widner H, Pearson TC, Larsen CP and Ekberg H. 2002. Simultaneous inhibition of B7 and LFA-1 signaling prevents rejection of discordant neural xenografts in mice lacking CD40L. Xenotransplantation 9(1):68-76.

Li JY, Englund E, Holton JL, Soulet D, Hagell P, Lees AJ, Lashley T, Quinn NP, Rehncrona S, Bjorklund Aand others. 2008. Lewy bodies in grafted neurons in subjects with Parkinson's disease suggest host-to-graft disease propagation. Nat Med 14(5):501-3.

Lindvall O and Kokaia Z. 2010. Stem cells in human neurodegenerative disorders--time for clinical translation? J Clin Invest 120(1):29-40.

Lindvall O, Kokaia Z and Martinez-Serrano A. 2004. Stem cell therapy for human neurodegenerative disorders-how to make it work. Nat Med 10 Suppl:S42-50.

Madri JA. 2009. Modeling the neurovascular niche: implications for recovery from CNS injury. J Physiol Pharmacol 60 Suppl 4:95-104.

Marion DW, Pollack IF and Lund RD. 1990. Patterns of immune rejection of mouse neocortex transplanted into neonatal rat brain, and effects of host immunosuppression. Brain Res 519(1-2):133-43.

Mason DW, Charlton HM, Jones AJ, Lavy CB, Puklavec M and Simmonds SJ. 1986. The fate of allogeneic and xenogeneic neuronal tissue transplanted into the third ventricle of rodents. Neuroscience 19(3):685-94.

Mendez I, Sanchez-Pernaute R, Cooper O, Vinuela A, Ferrari D, Bjorklund L, Dagher A and Isacson O. 2005. Cell type analysis of functional fetal dopamine cell suspension transplants in the striatum and substantia nigra of patients with Parkinson's disease. Brain 128(Pt 7):1498-510.

Mendez I, Vinuela A, Astradsson A, Mukhida K, Hallett P, Robertson H, Tierney T, Holness R, Dagher A, Trojanowski JQand others. 2008. Dopamine neurons implanted into 
people with Parkinson's disease survive without pathology for 14 years. Nat Med 14(5):507-9.

Moalem G, Leibowitz-Amit R, Yoles E, Mor F, Cohen IR and Schwartz M. 1999. Autoimmune $\mathrm{T}$ cells protect neurons from secondary degeneration after central nervous system axotomy. Nat Med 5(1):49-55.

Neumann J, Gunzer M, Gutzeit HO, Ullrich O, Reymann KG and Dinkel K. 2006. Microglia provide neuroprotection after ischemia. FASEB J 20(6):714-6.

Odeberg J, Piao JH, Samuelsson EB, Falci S and Akesson E. 2005. Low immunogenicity of in vitro-expanded human neural cells despite high MHC expression. J Neuroimmunol 161(1-2):1-11.

Oertel J, Samii M and Walter GF. 2004. Fetal allogeneic dopaminergic cell suspension grafts in the ventricular system of the rat: characterization of transplant morphology and graft-host interactions. Acta Neuropathol 107(5):421-7.

Okura Y, Tanaka R, Ono K, Yoshida S, Tanuma N and Matsumoto Y. 1997. Treatment of rat hemiparkinson model with xenogeneic neural transplantation: tolerance induction by anti-T-cell antibodies. J Neurosci Res 48(5):385-96.

Olstorn H, Moe MC, Roste GK, Bueters T and Langmoen IA. 2007. Transplantation of stem cells from the adult human brain to the adult rat brain. Neurosurgery 60(6):1089-98; discussion 1098-9.

Pakzaban P and Isacson O. 1994. Neural xenotransplantation: reconstruction of neuronal circuitry across species barriers. Neuroscience 62(4):989-1001.

Pastrana E, Cheng LC and Doetsch F. 2009. Simultaneous prospective purification of adult subventricular zone neural stem cells and their progeny. Proc Natl Acad Sci U S A 106(15):6387-92.

Pluchino S, Gritti A, Blezer E, Amadio S, Brambilla E, Borsellino G, Cossetti C, Del Carro U, Comi G, t Hart Band others. 2009. Human neural stem cells ameliorate autoimmune encephalomyelitis in non-human primates. Ann Neurol 66(3):343-54.

Pluchino S, Muzio L, Imitola J, Deleidi M, Alfaro-Cervello C, Salani G, Porcheri C, Brambilla E, Cavasinni F, Bergamaschi Aand others. 2008. Persistent inflammation alters the function of the endogenous brain stem cell compartment. Brain 131(Pt 10):2564-78.

Pluchino S, Quattrini A, Brambilla E, Gritti A, Salani G, Dina G, Galli R, Del Carro U, Amadio S, Bergami Aand others. 2003. Injection of adult neurospheres induces recovery in a chronic model of multiple sclerosis. Nature 422(6933):688-94.

Pluchino S, Zanotti L, Rossi B, Brambilla E, Ottoboni L, Salani G, Martinello M, Cattalini A, Bergami A, Furlan Rand others. 2005. Neurosphere-derived multipotent precursors promote neuroprotection by an immunomodulatory mechanism. Nature 436(7048):266-71.

Popa-Wagner A, Buga AM and Kokaia Z. 2009. Perturbed cellular response to brain injury during aging. Ageing Res Rev.

Reynolds BA and Weiss S. 1992. Generation of neurons and astrocytes from isolated cells of the adult mammalian central nervous system. Science 255(5052):1707-10.

Rezzani R. 2006. Exploring cyclosporine A-side effects and the protective role-played by antioxidants: the morphological and immunohistochemical studies. Histol Histopathol 21(3):301-16.

Romanko MJ, Rola R, Fike JR, Szele FG, Dizon ML, Felling RJ, Brazel CY and Levison SW. 2004. Roles of the mammalian subventricular zone in cell replacement after brain injury. Prog Neurobiol 74(2):77-99. 
Rota Nodari L, Ferrari D, Giani F, Bossi M, Rodriguez-Menendez V, Tredici G, Delia D, Vescovi AL and De Filippis L. 2010. Long-Term Survival of Human Neural Stem Cells in the Ischemic Rat Brain upon Transient Immunosuppression. PLoS One 5(11):e14035.

Schwartz M and Moalem G. 2001. Beneficial immune activity after CNS injury: prospects for vaccination. J Neuroimmunol 113(2):185-92.

Shihabuddin LS, Horner PJ, Ray J and Gage FH. 2000. Adult spinal cord stem cells generate neurons after transplantation in the adult dentate gyrus. J Neurosci 20(23):8727-35.

Streit WJ. 2002. Microglia and the response to brain injury. Ernst Schering Res Found Workshop(39):11-24.

Suhonen JO, Peterson DA, Ray J and Gage FH. 1996. Differentiation of adult hippocampusderived progenitors into olfactory neurons in vivo. Nature 383(6601):624-7.

Temple S. 2001. The development of neural stem cells. Nature 414(6859):112-7.

Temple S and Alvarez-Buylla A. 1999. Stem cells in the adult mammalian central nervous system. Curr Opin Neurobiol 9(1):135-41.

Ubiali F, Nava S, Nessi V, Frigerio S, Parati E, Bernasconi P, Mantegazza R and Baggi F. 2007. Allorecognition of human neural stem cells by peripheral blood lymphocytes despite low expression of MHC molecules: role of TGF-beta in modulating proliferation. Int Immunol 19(9):1063-74.

Weiss S, Reynolds BA, Vescovi AL, Morshead C, Craig CG and van der Kooy D. 1996. Is there a neural stem cell in the mammalian forebrain? Trends Neurosci 19(9):387-93.

Wennersten A, Holmin S, Al Nimer F, Meijer X, Wahlberg LU and Mathiesen T. 2006. Sustained survival of xenografted human neural stem/progenitor cells in experimental brain trauma despite discontinuation of immunosuppression. Exp Neurol 199(2):339-47.

Wood MJ, Sloan DJ, Wood KJ and Charlton HM. 1996. Indefinite survival of neural xenografts induced with anti-CD4 monoclonal antibodies. Neuroscience 70(3):775-89.

Yoles E, Hauben E, Palgi O, Agranov E, Gothilf A, Cohen A, Kuchroo V, Cohen IR, Weiner $\mathrm{H}$ and Schwartz M. 2001. Protective autoimmunity is a physiological response to CNS trauma. J Neurosci 21(11):3740-8.

Zhang R, Zhang Z, Wang L, Wang Y, Gousev A, Zhang L, Ho KL, Morshead C and Chopp M. 2004. Activated neural stem cells contribute to stroke-induced neurogenesis and neuroblast migration toward the infarct boundary in adult rats. J Cereb Blood Flow Metab 24(4):441-8.

Ziv Y, Avidan H, Pluchino S, Martino G and Schwartz M. 2006a. Synergy between immune cells and adult neural stem/progenitor cells promotes functional recovery from spinal cord injury. Proc Natl Acad Sci U S A 103(35):13174-9.

Ziv Y, Ron N, Butovsky O, Landa G, Sudai E, Greenberg N, Cohen H, Kipnis J and Schwartz M. 2006b. Immune cells contribute to the maintenance of neurogenesis and spatial learning abilities in adulthood. Nat Neurosci 9(2):268-75. 


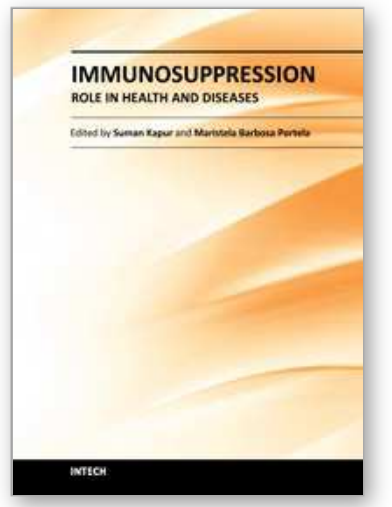

\author{
Immunosuppression - Role in Health and Diseases \\ Edited by Dr. Suman Kapur
}

ISBN 978-953-51-0152-9

Hard cover, 470 pages

Publisher InTech

Published online 24, February, 2012

Published in print edition February, 2012

A need for a book on immunology which primarily focuses on the needs of medical and clinical research students was recognized. This book, "Immunosuppression - Role in Health and Diseases" is relatively short and contains topics relevant to the understanding of human immune system and its role in health and diseases. Immunosuppression involves an act that reduces the activation or efficacy of the immune system. Therapeutic immunosuppression has applications in clinical medicine, ranging from prevention and treatment of organ/bone marrow transplant rejection, management of autoimmune and inflammatory disorders. It brings important developments both in the field of molecular mechanisms involved and active therapeutic approaches employed for immunosuppression in various human disease conditions. There was a need to bring this information together in a single volume, as much of the recent developments are dispersed throughout biomedical literature, largely in specialized journals. This book will serve well the practicing physicians, surgeons and biomedical scientists as it provides an insight into various approaches to immunosuppression and reviews current developments in each area.

\title{
How to reference
}

In order to correctly reference this scholarly work, feel free to copy and paste the following:

L. De Filippis, L. Rota Nodari and Maurizio Gelati (2012). Low Immunogenic Potential of Human Neural Stem Cells, Immunosuppression - Role in Health and Diseases, Dr. Suman Kapur (Ed.), ISBN: 978-953-51-0152-9, InTech, Available from: http://www.intechopen.com/books/immunosuppression-role-in-health-anddiseases/low-immunogenic-potential-of-human-neural-stem-cells

\section{INTECH}

open science | open minds

\section{InTech Europe}

University Campus STeP Ri

Slavka Krautzeka 83/A

51000 Rijeka, Croatia

Phone: +385 (51) 770447

Fax: +385 (51) 686166

www.intechopen.com

\section{InTech China}

Unit 405, Office Block, Hotel Equatorial Shanghai

No.65, Yan An Road (West), Shanghai, 200040, China 中国上海市延安西路65号上海国际贵都大饭店办公楼405单元

Phone: +86-21-62489820

Fax: +86-21-62489821 
(C) 2012 The Author(s). Licensee IntechOpen. This is an open access article distributed under the terms of the Creative Commons Attribution 3.0 License, which permits unrestricted use, distribution, and reproduction in any medium, provided the original work is properly cited. 